\title{
Geociências
}

\section{Maciços graníticos como rochas ornamentais na região nordeste do Estado do Amazonas: uma perspectiva de investimento para a cidade de Manaus}

\author{
(Solid granite used as ornamental stones in \\ the northeastern region of the State of \\ Amazonas, Brazil: an investment perspective \\ for the City of Manaus)
}

\section{Resumo}

O crescimento populacional de Manaus tem impulsionado o setor de rochas ornamentais e revestimentos a buscar matéria-prima de qualidade e beleza (granitos, gnaisses, mármores, etc.) na região sudeste do país a um custo elevado em até seis vezes. Entretanto a região nordeste do Amazonas hospeda maciços graníticos paleoproterozóicos com características ornamentais, os quais têm sido extraídos apenas para a produção de brita. Esse trabalho apresenta informações texturais, petrográficas, geoquímicas e de índices tecnológicos (porosidade, densidade, absorção d'água, compressão uniaxial, pulsos ultra-sônicos, resistência à flexão e desgaste Amsler) obtidas em cinco maciços graníticos expostos no nordeste do Amazonas. Tais informações sugerem que esses maciços graníticos podem ser utilizados como rochas ornamentais, porém em ambientes de moderado trânsito, baixa umidade e livres de ataques ácidos. Considerando os parâmetros técnicos favoráveis e a relativa proximidade das pedreiras da cidade de Manaus (cerca de 140 a $240 \mathrm{~km}$ ), a qual é um centro consumidor com 2 milhões de habitantes, o investimento no setor extrativista de rochas com fins ornamentais na região nordeste do Amazonas torna-se uma opção, no mínimo, interessante para o setor empresarial.

Palavras-chave: Estado do Amazonas, Manaus, rochas ornamentais, ensaio tecnológicos, investimentos no setor mineral.

\section{Valmir da Silva Souza \\ Instituto de Geociências, Universidade de Brasília/Programa de Pós- \\ Graduação em Geociências Universidade Federal do Amazonas E-mail:vsouza@unb.br}


paleoproterozoic granitic massifs with great potential for use as ornamental stones, which have onely been extracted for crushed-stone production. This paper presents the textural, petrographic, and geochemical characteristics, as well as technological indices (porosity, density, water absorption, uniaxial compression, ultrasonic pulses, resistance to flexion and Amsler degeneration) for samples from five granitic massifs exposed in the northeastern region of the State of Amazonas. The obtained data suggest that the granite massifs can be used as ornamental stones, but applicable in places with moderate transit, low humidity and free of acidic attacks. Considering the favorable technical parameters and the relative proximity of the granite massifs to the City of Manaus (about 140 to 240 $\mathrm{km})$, which is a consumer centre with 2 million inhabitants, the investment in the extraction of ornamental stones in the northeast of Amazonas becomes an option, at least, interesting for the business sector.

Keywords: State of Amazonas, City of Manaus, ornamental stones, technological analyses, investment in the mineral sector.

\section{Introdução}

A cidade de Manaus vem experimentando, nos últimos cinco anos, um progressivo e acelerado crescimento populacional, o qual impulsiona o setor da construção civil, principalmente através da verticalização urbana da cidade, criando espaço para um mercado competitivo. Nesse contexto, o setor de rochas ornamentais e de revestimentos do Amazonas é forçado a buscar matériaprima de qualidade e beleza (granitos, gnaisses, ardósias, mármores, etc.) na região sudeste do país ou até mesmo no vizinho Estado de Roraima, como alternativas para atender uma clientela cada vez mais exigente. Entretanto o Estado do Amazonas apresenta características geológicas favoráveis à presença de maciços graníticos com características ornamentais, distribuídos, principalmente, nos municípios de Presidente Figueiredo, Barcelos e São Gabriel da Cachoei- ra (Araújo Neto \& Moreira, 1976; Almeida et al., 2002, Valério, 2006, Reis et al., 2006). Os municípios de Presidente Figueiredo e Barcelos já se destacam como importantes centros produtores de brita (granito triturado) para o setor da construção civil de Manaus, cuja produção é facilmente transportada por via terrestre ou fluvial (Figura 1). Entretanto, até pela falta de experiência ou da carência de informações técnicas para o empresariado local e nacional, muitas dessas pedreiras para brita são subutilizadas, pois estão instaladas sobre maciços graníticos com características geológicas ideais para o setor de ornamentais e revestimentos.

Esse trabalho apresenta informações geológicas e resultados de ensaios físicos realizados em cinco dos maciços graníticos encontrados nos municípios de Presidente Figueiredo e Barcelos (AM). Tais informações buscam fornecer subsídios que auxiliem na implantação de futuros investimentos no setor de rochas ornamentais na região nordeste do Estado do Amazonas, cujo principal pólo consumidor está na capital Manaus com cerca de 2 milhões de habitantes.

\section{Materias e métodos}

O desenvolvimento desse trabalho envolveu duas etapas de campo para uma avaliação geológica simplificada dos maciços graníticos, acompanhada de coleta de amostras para as subseqüentes análises petrográficas e ensaios tecnológicos. As análises petrográficas foram realizadas no laboratório de microscopia do Departamento de Geociências da UFAM, enquanto que as informações sobre a composição geoquímica foram extraídas dos trabalhos de Araújo Neto e Moreira (1976), Valério (2006), Valério et al. (2006) e Souza et al. (2006). Os ensaios físicos com aplicabilidade para rochas ornamentais (porosidade, densidade, absorção d'água, compressão uniaxial, pulsos ultra-sônicos, resistência à flexão e desgaste Amsler) foram realizados no Núcleo de Tecnologia da Universidade Federal do Ceará (NUTEC). Os parâmetros físicos aplicados estão normatizados segundo ABNT (1992) e foram comparados aos parâmetros propostos pela ASTM (1992) e Frazão e Frajallat (1995).

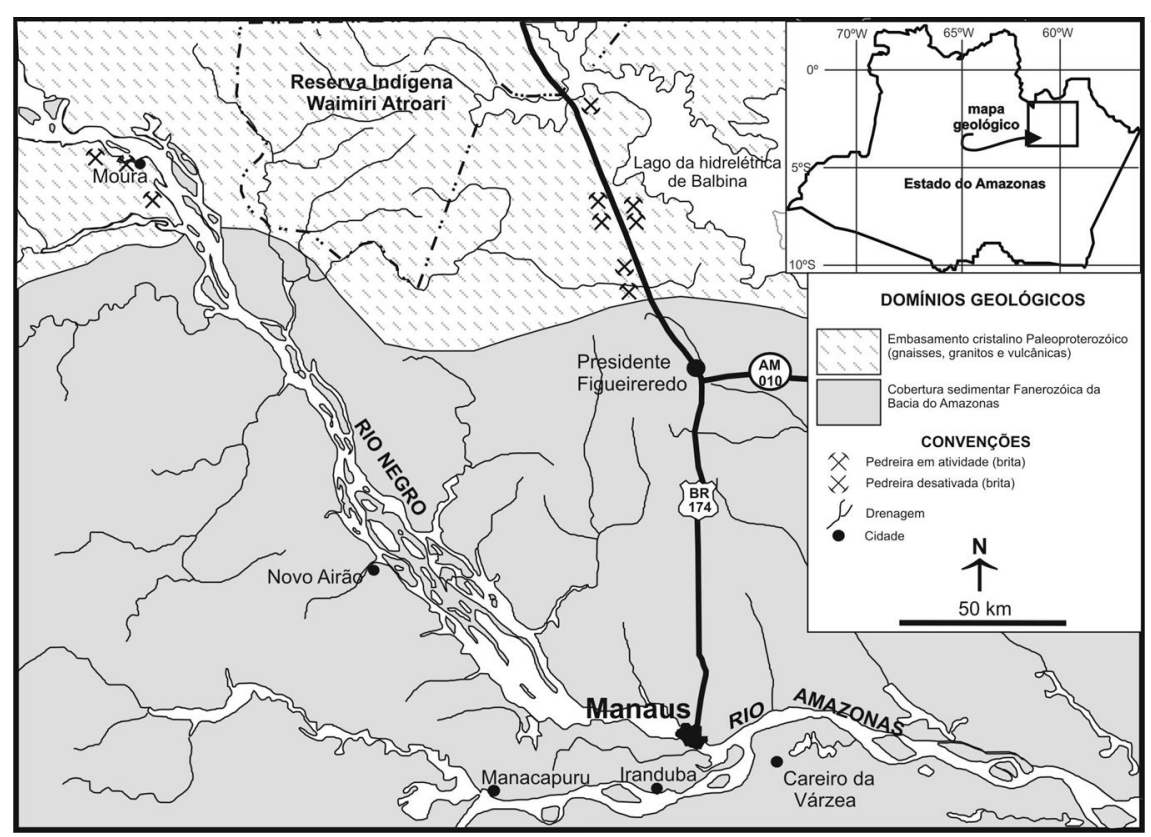

Figura 1 - Mapa geológico simplificado e de localização geográfica das áreas de ocorrência de frentes de lavra para extração de brita para construção civil. 


\section{Características geológicas e tecnológicas}

O município de Presidente Figueiredo hospeda a maioria dos maciços graníticos aqui estudados (Figura 1), os quais estão inseridos no contexto geológico das suítes paleoproterozóicas Água Branca e Mapuera (Araújo Neto e Moreira, 1976, Valério, 2006). Já, no município de Barcelos, apenas o maciço granítico Pedra do Gavião foi objeto dessa pesquisa, o qual está inserido no Complexo Jauaperi (Souza et al. 2006). Em geral, fora das frentes de extração de blocos para brita, esses maciços graníticos apresentam reduzidas áreas de exposição, as quais se mostram encobertas por latossolo com espessura entre 3 e $5 \mathrm{~m} \mathrm{e}$ floresta tropical.

\section{Petrografia}

Os maciços da Suíte Intrusiva Água Branca (SIAB) exibem cor cinza-claro (Figuras 2A e 2B), textura porfirítica ressaltada por fenocristais de feldspatos (microclínio e oligoclásio), com tamanho entre 2 e $5 \mathrm{~cm}$, imersos em matriz de granulação média a grossa. Os fenocristais são zonados e pertitizados, enquanto a matriz é constituída por microclínio (36-40\% em volume), quartzo (33-36\%), oligoclásio $\left(\mathrm{An}_{19-25} 22-25 \%\right)$ e biotita (5-8\%), definindo composição modal QAP entre sieno e monzogranítica. Por vezes, a rocha exibe marcante intercrescimento granofírico. Os cristais de microclínio e oligoclásio exibem bordas pouco serrilhadas e estão parcialmente sericitizados, enquanto o quartzo exibe extinção ondulante e a biotita está parcialmente cloritizada. Essa trama mineral apresenta ótimo grau de entrelaçamento, cujos contatos são côncavos-convexos a serrilhados, com grau de microfissuras inter e intragrãos baixo $\left(0,083 / \mathrm{mm}^{2}\right)$, de pouca comunicabilidade e sem orientação preferencial.

Os maciços da Suíte Intrusiva Mapuera (SIM) chegam a formar estruturas batolíticas, abrangendo áreas entre 220
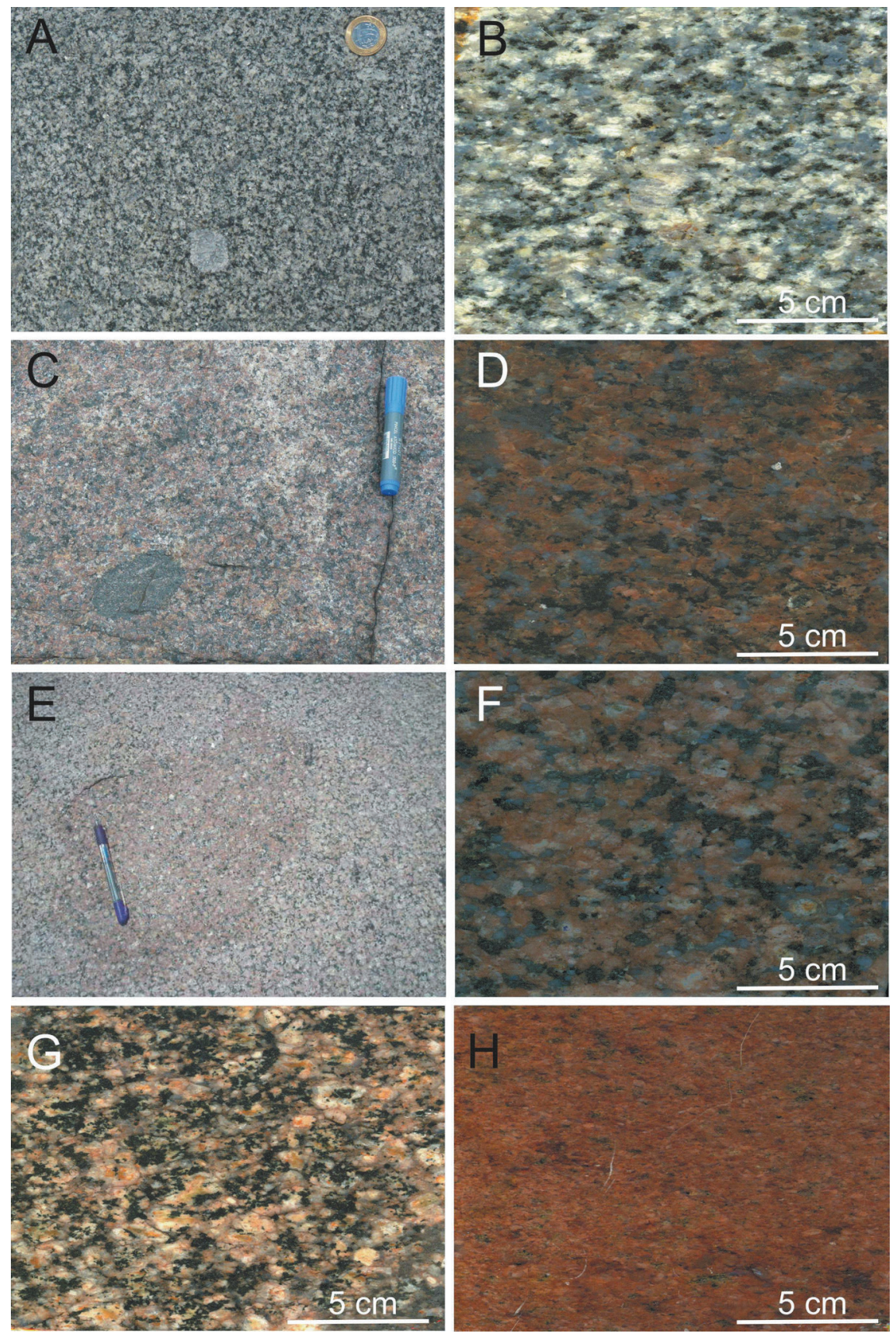

Figura 2 - Aspectos texturais dos maciços graníticos estudados em escala de afloramento e em amostras de prova polidas: Em A e B, granito da SIAB (Terra Preta Nobre); em C e D, granito Abonari (Abonari Real); em E e F, granito Pedra do Gavião (Vermelho Moura); em G, granito da SIM (Castanhal Clássico); e H, granito da SIM (Rosa Esperança).

e $250 \mathrm{~km}^{2}$, como são os casos dos granitos São Gabriel e Abonari (Figuras $2 \mathrm{C}$ e 2D). Em geral, essas rochas exibem cor vermelha com matiz azulado, textura inequigranular de granulação média a grossa, contendo eventuais xenólitos e encraves máficos. São constituídas por microclínio pertítico (57-60\% em volume), quartzo (20-23\%), oligoclásio $\left(\mathrm{An}_{18-25} 10-13 \%\right)$, hornblenda (3-6\%) e biotita (1-3\%), definindo composição QAP sienogranítica. Na SIM são identificadas variações petrográficas representadas, principalmente, por K-feldspato 
granito de cor rosa-alaranjado (Figura $2 \mathrm{H}$ ), constituído por microclínio pertítico (47-52\%), quartzo (38-43\%), oligoclásio $\left(\mathrm{An}_{17-24} 12-14 \%\right)$ e biotita (1-2\%). O microclínio e o oligoclásio mostram-se parcialmente sericitizados, o quartzo exibe extinção ondulante, enquanto a hornblenda e a biotita estão parcialmente desestabilizadas para clorita. Em geral, a trama mineral também apresenta ótimo grau de entrelaçamento, com contatos côncavo-convexos a serrilhados, grau de microfissuras inter e intragrãos baixo $\left(0,08-0,12 \mathrm{~mm}^{2}\right)$, de pouca comunicabilidade e sem orientação preferencial.

O maciço granítico Pedra do Gavião exibe formato de um stock elíptico com área em torno de $100 \mathrm{~km}^{2}$, localizado às margens do rio Negro. Exibe cor vermelho com matiz azulado (Figuras 2E e 2F), textura inequigranular de granulação média a grossa, contendo eventuais xenólitos e raros encraves máficos. É constituído por microclínio pertítico (45-50\% em volume), quartzo (24-31\%), oligoclásio $\left(\mathrm{An}_{16-20} 15-18 \%\right)$, hornblenda (5-10\%) e biotita (2-4\%), definindo composição QAP sienogranítica. O microclínio e o oligoclásio estão pouco a moderadamente sericitizados, o quartzo exibe forte extinção ondulante, enquanto a hornblenda e a biotita formam agregados parcialmente cloritizados. Essa trama mineral também possui ótimo grau de entrelaçamento, com contatos côncavo-convexos a serrilhados, com grau de microfissuras inter e intragrãos (quartzo e feldspatos) baixo a moderado $\left(0,15 / \mathrm{mm}^{2}\right)$, de moderada comunicabilidade e sem orientação preferencial.

\section{Geoquímica}

A Tabela 1 contém os intervalos da composição química, em termos de seus elementos maiores, das suítes graníticas aqui estudadas. Em geral, essas rochas possuem assinatura geoquímica subalcalina de alto potássio, com índice da saturação em alumina (ISA) variando na interface dos campos meta e peraluminoso (Araújo Neto \& Moreira, 1976, Valério, 2006, Valério et al., 2006, Souza et al. 2006).

Tabela 1 - Variação na composição química, em termos dos elementos maiores (em \% peso), dos maciços graníticos estudados (SIAB = Suíte Intrusiva Água Branca, SIM = Suíte Intrusiva Mapuera, (1) = compilado de Valério, 2006 e Valério et al., 2006, $(2)=$ compilado de Araújo Neto \& Moreira, 1976 e Valério, 2006, (3)= compilado de Souza et al., 2006).

\begin{tabular}{c|c|c|c}
\hline $\begin{array}{c}\text { Maciços } \\
\text { graníticos }\end{array}$ & SIAB (1) & SIM (2) & $\begin{array}{c}\text { Pedra do } \\
\text { Gavião (3) }\end{array}$ \\
\hline $\mathbf{S i O}_{2}$ & $66,9-72,6$ & $72-74$ & $70-72$ \\
\hline $\mathrm{TiO}_{2}$ & $0,2-0,34$ & $0,1-0,5$ & $0,3-0,4$ \\
\hline $\mathrm{Al}_{2} \mathrm{O}_{3}$ & $14,1-16,5$ & $13-17,7$ & $13,1-13,7$ \\
\hline $\mathrm{Fe}_{2} \mathrm{O}_{3}$ (total) & $1,7-3,5$ & $1,7-2,7$ & $3,1-3,7$ \\
\hline $\mathbf{M n O}$ & $0,03-0,07$ & $0,05-0,08$ & $0,06-0,07$ \\
\hline $\mathbf{M g O}$ & $0,3-1,3$ & $0,22-0,47$ & $0,08-0,15$ \\
\hline $\mathbf{C a O}$ & $1,3-2,9$ & $0,5-1,3$ & $0,94-1,11$ \\
\hline $\mathbf{N a}_{2} \mathrm{O}$ & $3,7-4,7$ & $3,3-4,4$ & $3,4-3,6$ \\
\hline $\mathbf{K}_{2} \mathrm{O}$ & $3,6-4,7$ & $4,7-5,5$ & $5,9-6,2$ \\
\hline $\mathbf{P}_{2} \mathrm{O}_{5}$ & $0,06-0,16$ & $0,01-0,08$ & $0,04-0,06$ \\
\hline $\mathbf{P F}$ & $0,7-1$ & $0,5-0,8$ & $0,2-0,4$ \\
\hline $\mathrm{Total}$ & $99,6-99,8$ & $99,8-99,9$ & $99,6-99,8$ \\
\hline
\end{tabular}

\section{6. Î́ndices físicos}

A Tabela 2 contém as características tecnológicas representadas pelos índices físicos de porosidade, densidade, absorção d'água, compressão uniaxial, pulsos ultra-sônicos, resistência à flexão e desgaste Amsler (ABNT, 1992), obtidos para os maciços graníticos estudados. Tais valores são comparados aos índices físicos propostos pela ASTM (1992) e Frazão e Frajallat (1995). Nessa tabela, foram atribuídos aos litotipos graníticos estudados nomes comerciais de fantasia, a saber: a)Terra Preta Nobre, para os maciços de cor cinza-claro e textura porfirítica da SIAB (Figura 2); b) Castanhal Clássico, Abonari Real e Rosa-Esperança, para os maciços da SIM; e c) Vermelho-Moura, para o maciço granítico Pedra do Gavião inserido no Complexo Jauaperi.

Os resultados demonstram que, comparativamente, os maciços graníticos Castanhal Clássico e Terra Preta Nobre, por apresentarem maior densidade aparente e menores índices de porosidade e absorção, apresentam alta resistência mecânica e, conseqüentemente, maior durabilidade em relação aos demais maciços. Entretanto a presença dos silicatos ferromagnesianos (biotitas e anfibólios) no maciço Castanhal Clássico pode representar um fator limitante para a aplicabilidade dessa rocha em ambientes úmidos ou sujeitos aos ataques ácidos, pois esses minerais oxidam-se facilmente, produzindo manchas de cores amareladas ou acastanhadas, que podem comprometer a qualidade estética dos materiais.

Já o granito Rosa-Esperança, devido aos índices de porosidade e absorção relativamente elevados (Tabela 2), também tem sua aplicabilidade comprometida para ambientes úmidos. Por outro lado, os maciços graníticos Abonari Real e Vermelho-Moura mostram índices físicos que os credenciam para aplicabilidade em ambientes de moderado trân- 
Elayne Cristina Andrade de Sousa Maas et al.

Tabela 2 - Valores dos índices físicos obtidos para os diferentes maciços graníticos estudados (SIAB = Suíte Intrusiva Água Branca, SIM = Suíte Intrusiva Mapuera, CC = Castanhal Clássico, VM = Vermelho-Moura, AR = Abonari Real, TPN = Terra Preta Nobre, RE = Rosa esperança).

\begin{tabular}{|c|c|c|c|c|c|c|c|}
\hline \multirow[b]{3}{*}{ Índices Físicos } & \multicolumn{5}{|c|}{ Maciços graníticos } & \multirow{2}{*}{\multicolumn{2}{|c|}{$\begin{array}{l}\text { Padrões utilizados para } \\
\text { os índices físicos }\end{array}$}} \\
\hline & \multirow{2}{*}{$\begin{array}{l}\text { SIAB } \\
\text { TPN }\end{array}$} & \multicolumn{3}{|c|}{ SIM } & \multirow{2}{*}{\begin{tabular}{|c|}
$\begin{array}{c}\text { Pedra do } \\
\text { Gavião }\end{array}$ \\
VM \\
\end{tabular}} & & \\
\hline & & AR & RE & CC & & $\begin{array}{l}\text { ASTM } \\
\text { (1992) }\end{array}$ & $\begin{array}{c}\text { Frazão \& } \\
\text { Farjallat } \\
(1995)\end{array}$ \\
\hline Porosidade (volume \%) & 0,35 & 0,46 & 0,87 & 0,29 & 0,68 & n.e. & $\leq 1$ \\
\hline Densidade seca $\left(\mathrm{kg} / \mathrm{m}^{3}\right)$ & 2,67 & 2,64 & 2,62 & 2,71 & 2,65 & $\geq 2,560$ & $\geq 2,550$ \\
\hline Densidade saturada $\left(\mathbf{k g} / \mathbf{m}^{3}\right)$ & 2,68 & 2,65 & 2,63 & 2,72 & 2,66 & n.e. & n.e. \\
\hline Absorção (\% em peso) & 0,13 & 0,18 & 0,35 & 0,10 & 0,25 & $\leq 0,40$ & $\leq 0,40$ \\
\hline Resistência à compressão (MPa) & 151,6 & 164,9 & 253,8 & 209,9 & 120,5 & $\geq 131$ & $\geq 100$ \\
\hline Resistência à flexão (MPa) & 22,3 & 15,8 & - & - & 10,5 & $\geq 10,34$ & $\geq 10$ \\
\hline Desgaste Amsler (mm) & 0,46 & 0,65 & 0,33 & 0,68 & 0,50 & n.e. & $\leq 1$ \\
\hline Pulso ultra-sônico (m/s) & 6594 & 6123 & - & - & 5474 & n.e. & $\geq 4000$ \\
\hline
\end{tabular}

n.e. = não especificado

sito e umidade. Entretanto o maciço Vermelho-Moura apresentou percentual de microfissuras mais elevado do que os demais maciços, o que é atribuído à ação dos explosivos durante a extração de blocos para brita.

\section{Considerações finais}

O crescimento imobiliário da cidade de Manaus é marcado, principalmente, pelo acelerado surgimento de condomínios residenciais, comerciais e shopping centers de média e alta classes, caracterizados por arquiteturas modernas e interiores de elevada beleza e bom-gosto. Nesse contexto, o setor de pisos e revestimentos local está importando seus materiais, principalmente da região sudeste do país, a um custo elevado em cerca de três a seis vezes, dependendo das características texturais e técnicas das rochas. Segundo informações verbais dos empresários locais, peças simples de granito cinza e de granito vermelho custam na região sudeste do país entre $\mathrm{R} \$ 75$ e $78,00 / \mathrm{m}^{2}$ e $\mathrm{R} \$ 98$ e $105,00 / \mathrm{m}^{2}$, as quais são comercializadas em Manaus a valores entre R\$ 135 e $155,00 / \mathrm{m}^{2}$ e $\mathrm{R} \$ 345$ e $375,00 / \mathrm{m}^{2}$, respectivamente.

Os maciços graníticos, na região nordeste do Estado do Amazonas, têm sido explotados apenas como brita para a construção civil. Entretanto as características texturais e físicas dos maciços graníticos aqui apresentados os credenciam como material a ser utilizado no segmento de rochas ornamentais, observadas determinadas condições para suas aplicações. Essas características técnicas favoráveis, somadas à proximidade das frentes de lavra das pedreiras em relação à capital Manaus, a qual é um centro consumidor com 2 milhões de habitantes e figura entre as dez cidades mais importantes do país, tornam o investimento, no setor extrativista de rochas com fins ornamentais, nessa região, uma opção, no mínimo, interessante para o setor empresarial local e nacional. Além do mais, uma frente de lavra, para rochas ornamentais, apresenta, em geral, uma perda de material em torno de 50 a $60 \%$, material este que poderia ser perfeitamente utilizado como brita, dinamizando a lavra, diminuindo o volume do pátio de rejeito, amenizando o impacto visual do ambiente, aumentando a receita e gerando mais empregos. Entretanto informações técnicas complementares ainda são necessárias para auxiliar na viabilidade de exploração desses maciços graníticos, tais como: a) espessura do capeamento de latossolo e floresta, b) regime tensão de fraturas, c) área e reserva medida para exploração, d) índices técnicos de fadiga térmica e de resistência ao ataque químico.

\section{Agradecimentos}

Ao Programa de Pós-Graduação em Geociências da UFAM pelo apoio e infra-estrutura dispensados. À FAPEAM pela concessão de bolsa de estudo à pri- 
Maciços graníticos como rochas ornamentais na região nordeste do Estado do Amazonas...

meira autora. Aos projetos Casadinho UFAM-UFPA (MCT/CNPq, Proc. N ${ }^{\circ}$ 620034/2006-8) e CT-Amazônia (MCT/CNPq Proc. No 575520/2008-6) pelo auxilio financeiro no custeio das análises. Ao geólogo Marcos Maas, pelo apoio durante as etapas de campo e conclusiva desse trabalho.

\section{Referências bibliográficas}

ABNT - ASSOCIAÇÃO BRASILEIRA DE NORMAS TÉCNICAS. Rochas para Revestimento, 1992 (registros de testes NBR 12763, 12042, 12764, 12766, 12767, 12768). 138p.

ALMEIDA, M.E., PINHEIRO, S.S., LUZARDO, R. Reconhecimento geológico ao longo dos rios Negro, Xié e Içana (Missão Tunuí), noroeste do Estado do Amazonas. Manaus: CPRM, 2002. 16p. (Relatório interno).
ARAÚJO NETO, H., MOREIRA, H. L. Projeto Estanho de Abonari, Brasília: MME/ DNPM/CPRM, 1976. v.1. 232p.

ASTM - AMERICAN SOCIETY FOR TESTING AND MATERIALS. Standard specification for granites dimension stone, 1992. (C 615).

FRAZÃO, E.B., FARJALLAT, J.E.S. Características tecnológicas das principais rochas silicáticas brasileiras usadas como pedras de revestimento. In: CONGR. INTER. PEDRA NATURAL 1º ${ }^{\circ}$ 1995, Lisboa, Actas... Lisboa: 1995. p. 47-58.

REIS, N.J., ALMEIDA, M.E., RIKER, S.L., FERREIRA, A.L. Geologia e recursos minerais do Estado do Amazonas. Programa de Geologia do Brasil (mapas geológicos estaduais, escala 1:1.000.000), Manaus, MME/CPRM/CIAMA: 2006. 125p.

SOUZA, A.G.H., SOUZA, V.S., DANTAS, E.L., VALÉRIO, C.S., LAUX, J.H., SILVA, A.J.M., FERREIRA, J.R. Petrografia, geoquímica e idade U-Pb do granito Pedra do Gavião, baixo curso do Rio Negro (AM). In: CONGR. BRAS. GEOL. 43, 2006, Aracajú, Anais... Aracajú: SBG, 2006. p.127.

VALÉRIO, C.S. Magmatismo Paleoproterozóico do estremo sul do Escudo das Guianas, município de Presidente Figueiredo (AM): geologia, geoquímica e geocronologia PbPb em zircão. Manaus: Departamento de Geociências, UFAM, 2006. 112p. (Dissertação de Mestrado).

VALÉRIO, C.S., SOUZA, V.S., MACAMBIRA, M.B., GALARZA, M.A. Geoquímica e Geocronologia $\mathrm{Pb}-\mathrm{Pb}$ da Suíte Intrusiva Água Branca, município de Presidente Figueiredo (AM): evidências de colisão no Paleoproterozóico da Amazônia Ocidental. Revista Brasileira de Geociências, v. 36, n. 2, p. 359-370, 2006.

Artigo recebido em 17/10/2008 e aprovado em 24/04/2009.

\section{A REM tem novo endereço: FUNDAÇÃO GORCEIX - REM Rua Carlos Walter Marinho Campos, 57 Bairro: Vila Itacolomy 35400-000 - Ouro Preto - MG (31) $3551-4730$ (31) 3559-7408 \\ $* * * * * * * *$ \\ www.rem.com.br}

